\title{
Temperature induced conformational transitions of elastin-like polypentapeptides studied by Raman and NMR spectroscopy
}

\author{
Jiří Dybal $^{\text {a,* }}$, Pavel Schmidt ${ }^{\text {a }}$, Dana Kurkováa ${ }^{\text {, Jaroslav Kříž }}{ }^{\text {a }}$, \\ José Carlos Rodríguez-Cabello $^{\mathrm{b}}$ and Matilde Alonso ${ }^{\mathrm{c}}$ \\ a Institute of Macromolecular Chemistry, Academy of Sciences of the Czech Republic, 16206 Prague 6, \\ Czech Republic \\ ${ }^{\mathrm{b}}$ Department of Condensed Matter, E.T.S.I.I., University of Valladolid, 47011 Valladolid, Spain \\ ${ }^{\mathrm{c}}$ Department of Analytical Chemistry, E.U.P., University of Valladolid, 47014 Valladolid, Spain
}

\begin{abstract}
Raman and NMR spectroscopy together with DFT quantum chemical calculations have been used to elucidate conformational changes occurring during inverse temperature transition in water solution of two elastin-like polypentapeptides, poly $\left(G_{1} V_{1} G_{2} V_{2} P\right)$ and poly $\left(A V_{1} G_{2} P\right)$. From the temperature dependences of Raman spectra and ${ }^{1} \mathrm{H}-{ }^{1} \mathrm{H}$ NOESY spectra follows that above the transition temperature a $\beta$ (II)-turn conformational structure is formed on the residue located between Pro and $\mathrm{Val}_{1}$.
\end{abstract}

\section{Introduction}

Under gradual heating elastin-like polypentapeptides undergo in aqueous solution a characteristic inverse temperature transition, at which the polypeptide molecules change reversibly their state leading to aggregation and eventually sedimentation [1,2]. In this study we examined changes of the conformational structure at the inverse temperature transition of two elastin-like polypentapeptides, poly $\left(\mathrm{G}_{1} \mathrm{~V}_{1} \mathrm{G}_{2} \mathrm{~V}_{2} \mathrm{P}\right)$ and poly $\left(\mathrm{AV}_{1} \mathrm{GV}_{2} \mathrm{P}\right)(\mathrm{G}=$ glycine, $\mathrm{V}=\mathrm{L}$-valine, $\mathrm{P}=\mathrm{L}$-proline, $\mathrm{A}=$ alanine $)$.

\section{Experimental section}

Poly $\left(G_{1} V_{1} G_{2} V_{2} P\right)$ and poly $\left(A_{1} G_{2} P\right)$ were synthesized following methods described earlier [3] and detailed characterization including mean molecular weight and polydispersivity of the final polymers can be found in $[4,5]$.

Raman spectra were measured at the $4 \mathrm{~cm}^{-1}$ resolution using a Bruker IFS 55 Fourier-transform infrared spectrometer equipped with a Raman module FRA 106. The spectra of water solutions, of suspensions, and of sediments were measured in sealed glass tubes, which were put into an evacuated Raman glass cell heated with warm air or cooled with cold nitrogen. The temperature of the sample was controlled electronically with an accuracy of $\pm 1{ }^{\circ} \mathrm{C}$.

${ }^{1} \mathrm{H}$ and ${ }^{13} \mathrm{C}$ NMR spectra of $5 \mathrm{wt} \%$ solutions of the polymer in $\mathrm{D}_{2} \mathrm{O}$ (99.8\% deuterated) and $\mathrm{H}_{2} \mathrm{O}$ using HMDS in a capillary as external standard were measured with a Bruker Avance DPX 300 spectrometer

\footnotetext{
${ }^{*}$ Corresponding author. Tel.: +420 2 20403387; Fax: +420 2 367981; E-mail: dybal@imc.cas.cz.
} 
(300.13 MHz resonance frequency for ${ }^{1} \mathrm{H}$ ) collecting $16 \mathrm{~K}\left({ }^{1} \mathrm{H}\right)$ or $32 \mathrm{~K}\left({ }^{13} \mathrm{C}\right)$ points in a quadrature detection. WALTZ16 proton decoupling was used in measuring ${ }^{13} \mathrm{C}$ spectra. 2D NOESY NMR experiments in $\mathrm{H}_{2} \mathrm{O}$ were performed in the phase-sensitive and quadrature detection modes with 2024 points in the $t_{2}$ dimension (spectral width $=3000 \mathrm{~Hz}$ ) and with $256 t_{1}$ experiments. A mixing time of $200 \mathrm{~ms}$ was used. Prior to Fourier transformation, the data in the $t_{1}$ and $t_{2}$ domain were multiplied by a shifted sine bell window function. Solvent peak was suppressed by selective presaturation of the peak during pulse delay between two consecutive acquisitions.

\section{Results and discussion}

\subsection{Raman spectroscopy}

Raman spectra of two elastin-like polymers, poly $\left(G_{1} V_{1} G_{2} V_{2} P\right)$ and poly $\left(A V_{1} G_{2} P\right)$ were measured in $\mathrm{H}_{2} \mathrm{O}$ at temperatures below and above the inverse temperature transition (approximately 299-300 K) (Fig. 1). Analysis of the spectral changes observed in the temperature and concentration dependences has shown [2] that polypentapeptides exhibit vibrations sensitive to both changes in the conformational structure of the polymer ( $\mathrm{C}-\mathrm{H}$ bending) and to local changes in the surrounding medium of the polymer chain caused by hydrophobic or hydrophilic interactions (C-H stretching). Compared with $7.5 \mathrm{wt} \%$ water solution the $\mathrm{C}-\mathrm{H}$ stretching band is shifted to lower wavenumbers by $6 \mathrm{~cm}^{-1}$ in $50 \mathrm{wt} \%$ water solution and the shift reaches $10 \mathrm{~cm}^{-1}$ for dry samples. Ab initio calculations of the interactions of model structure sequences of polypentapeptides with surrounding water clusters indicate that the observed frequency shifts are predominantly caused by blue-shifting hydrogen bonds $\mathrm{C}-\mathrm{H} \cdots \mathrm{OH}_{2}$. Therefore, the observed frequency shifts can be related to the changes in the intermolecular arrangement of water molecules in the vicinity of hydrophobic and hydrophilic groups of amino-acid residues.

On the other hand, an intense conformational transition is manifested in vibrational spectra especially by the appearance of new bands. Such is the appearance of the new band at $1413 \mathrm{~cm}^{-1}$ in the spectra of suspension of poly $\left(\mathrm{G}_{1} \mathrm{~V}_{1} \mathrm{G}_{2} \mathrm{~V}_{2} \mathrm{P}\right)$ formed by heating (Fig. 1). An analogous band in this region observed

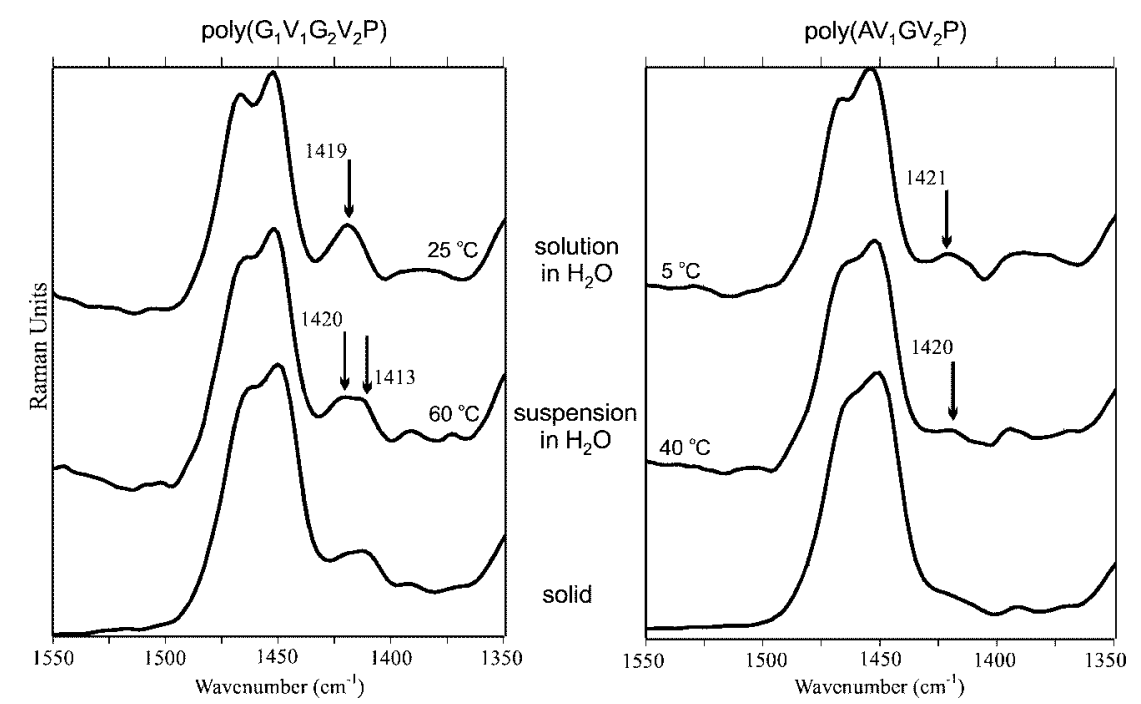

Fig. 1. Raman spectra of poly $\left(\mathrm{G}_{1} \mathrm{~V}_{1} \mathrm{G}_{2} \mathrm{~V}_{2} \mathrm{P}\right)$ and poly $\left(\mathrm{AV}_{1} \mathrm{GV}_{2} \mathrm{P}\right)$ in the $7.5 \mathrm{wt} \%$ solutions in $\mathrm{H}_{2} \mathrm{O}$ and in the solid state. 

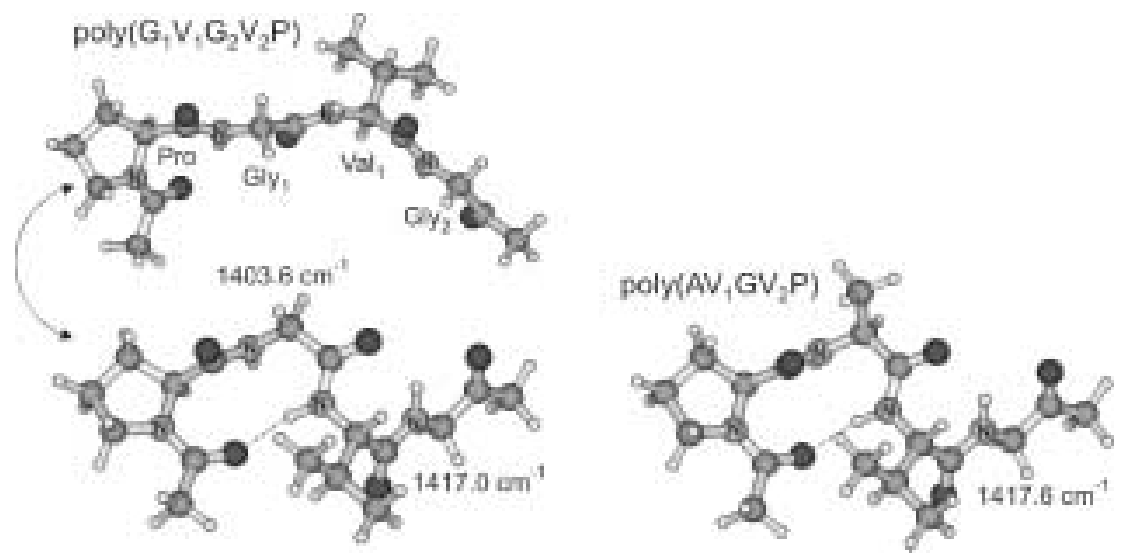

Fig. 2. Optimized geometries representing the structural segment $P G_{1} V_{1} G_{2}$ of poly $\left(G_{1} V_{1} G_{2} V_{2} P\right)$ and the segment $P A V_{1} G$ of poly $\left(\mathrm{AV}_{1} \mathrm{GV}_{2} \mathrm{P}\right)$ calculated at the B3LYP/6-31G(d) level, together with vibrational frequencies of the mode dominated by the glycine $\mathrm{CH}_{2}$ wagging vibrations.

in the Raman spectrum of polyglycine was assigned [6] to the $\mathrm{CH}_{2}$ wagging vibration. This assignment is confirmed by our $a b$ initio calculations on the model compound representing the chemical structure of the glycine residues with their close neighborhood in poly $\left(G_{1} V_{1} G_{2} V_{2} P\right)$ and poly $\left(A V_{1} G V_{2} P\right)$ (Fig. 2).

Calculations of the vibrational frequencies at the DFT level of theory [7] enabled us to follow the changes of the vibrational frequencies during the conformational transition (Fig. 2). The chains of poly $\left(\mathrm{G}_{1} \mathrm{~V}_{1} \mathrm{G}_{2} \mathrm{~V}_{2} \mathrm{P}\right)$ with mostly extended conformations present in the solution are represented by only one Raman vibrational band in this frequency region for both glycine residues in the pentapeptide, irrespective of their chemical neighborhood. After the conformational transition related to the formation of the $\beta$-spiral, a new band at lower frequency appears in this region corresponding to the newly formed $\beta$ (II)-turn conformation on one of the glycine units (Fig. 2). Our results are in accordance with the role of one of the glycine units in the structure of the $\beta$-spiral of polypentapeptides. This glycine is involved in the formation of $\beta$ (II)-turns stabilized intramolecularly by hydrogen bonds between valine residues (Fig. 2). The wagging vibration with the lower frequency corresponds to this $\beta$ (II)-turn conformation of the glycine unit [2]; the wagging vibration with the higher frequency corresponds to the other glycine unit maintaining the extended conformation in the $\beta$-spiral. This finding is here further extended by the Raman analysis of poly $\left(\mathrm{AV}_{1} \mathrm{GV}_{2} \mathrm{P}\right)$ with the first of the glycine residues $\left(\mathrm{Gly}_{1}\right)$ substituted by alanine (Figs 1 and 2). Only one band was found in the spectra of poly $\left(A V_{1} G V_{2} P\right)$ in the region of the glycine $\mathrm{CH}_{2}$ wagging vibrations with its frequency roughly the same below and above the transition temperature. Based on these facts, the $\beta(\mathrm{II})$-turn in poly $\left(\mathrm{G}_{1} \mathrm{~V}_{1} \mathrm{G}_{2} \mathrm{~V}_{2} \mathrm{P}\right)$ can be allocated to the $\mathrm{Gly}_{1}$ site.

\subsection{NMR spectroscopy}

Using a number of techniques of NMR, four different physical states of both polypentapeptides poly $\left(G_{1} V_{1} G_{2} V_{2} P\right)$ and poly $\left(A V_{1} G_{2} P\right)$ in aqueous solutions were discerned in different temperature regions: state I of an extended, statistically shaped fully hydrated polymer below the transition temperature; coiled pre-aggregation state II with occasional $\beta$ (II)-turns developing in a temperature region $299-303 \mathrm{~K}$ in the case of poly $\left(\mathrm{AV}_{1} \mathrm{GV}_{2} \mathrm{P}\right)$ and in a broader region in poly $\left(\mathrm{G}_{1} \mathrm{~V}_{1} \mathrm{G}_{2} \mathrm{~V}_{2} \mathrm{P}\right)$; tightly coiled, more compact state III in the region 303-313 K; aggregated and eventually sedimenting state IV above $313 \mathrm{~K}[8]$. 


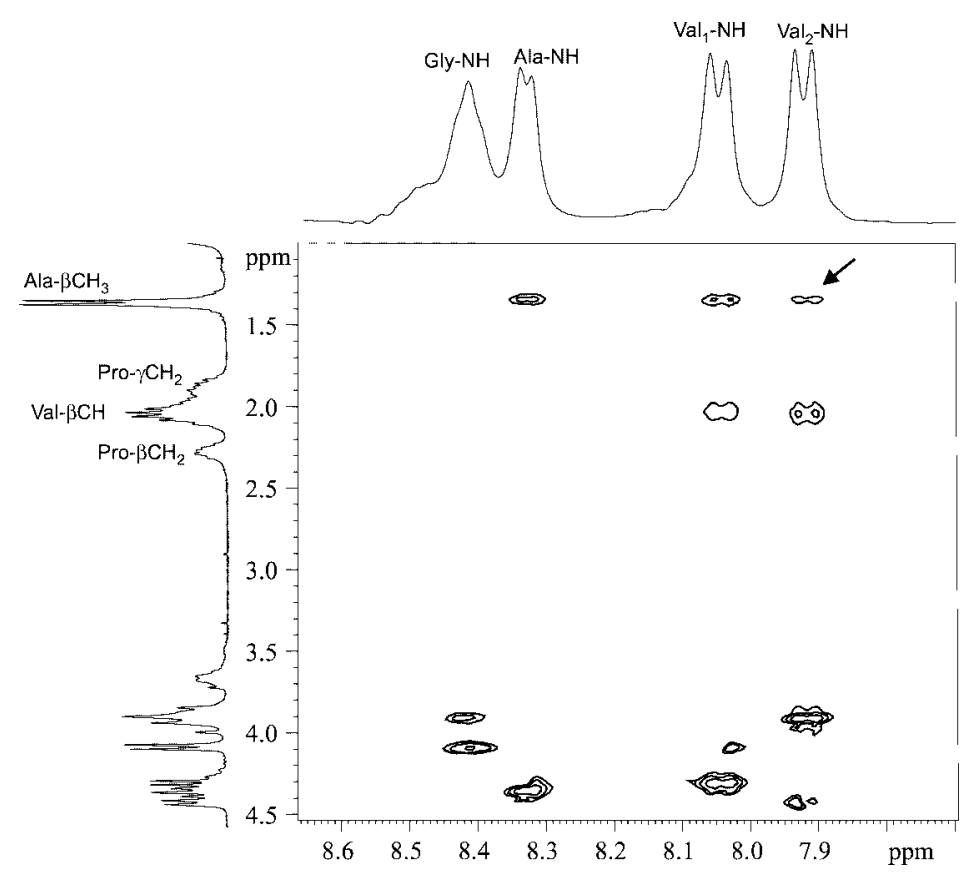

Fig. 3. Section of the ${ }^{1} \mathrm{H}-{ }^{1} \mathrm{H}$ NOESY spectrum of poly $\left(\mathrm{AV}_{1} \mathrm{GV}_{2} \mathrm{P}\right)$ measured at $301 \mathrm{~K}$. An arrow indicates the significant crosspeak between Ala- $\beta \mathrm{CH}_{3}$ and $\mathrm{Val}_{2}-\mathrm{NH}$.

One source of information on the conformational structures of the polypentapeptides is based on $J$-coupling constants obtained from the splitting of $\mathrm{NH}$ and vicinal $\mathrm{CH}$ or $\mathrm{CH}_{2}{ }^{1} \mathrm{H}$ signals. Values of the ${ }^{3} J_{\mathrm{NHCH}}$ coupling constants $(6.8-7.96 \mathrm{~Hz})$ and corresponding dihedral angles calculated using the Karplus relation indicate that the chains of both polypentapeptides are roughly straight, forming rather statistical coils in the state I (280-299 K). Under gradual heating there is observed an increase of the $J$-coupling constant for the $\mathrm{Val}_{1}$ residue in poly $\left(\mathrm{G}_{1} \mathrm{~V}_{2} \mathrm{G}_{1} \mathrm{~V}_{2} \mathrm{P}\right)$ at the transition temperature followed by an analogous change in $\mathrm{Val}_{2}$ at $311 \mathrm{~K}$, suggesting a change of conformation. However, changes of dihedral angles during the inverse temperature transition are not reflected with sufficient clearness by the $J$-coupling constants.

Other sources of information suitable for the conformational analysis is based on the nuclear Overhauser effect (NOE). In our case NOE effects are exceptionally weak due to molecular dynamics, so that the acquisition of a NOESY spectrum of a medium quality takes about 80 hours. Nevertheless, basic information could be obtained by this technique. In agreement with the above observations, NOESY spectra taken at a temperature just below transition show only the expected types of space connectivities, i.e., $G_{1} V_{1} G_{2}, G_{2} V_{2} P, V_{2} P G_{1}$ for poly $\left(G_{1} V_{1} G_{2} V_{2} P\right)$ and $A V_{1} G, G_{2} P, V_{2} P A$ for poly $\left(A V_{1} G V_{2} P\right)$, but no evidence for a spatial vicinity of groups, which would suggest stable conformations characteristic of a $\beta$ or $\gamma$ turn below the transition temperature. However, Fig. 3 shows a weak crosspeak in the NOESY spectrum of poly $\left(\mathrm{AV}_{1} \mathrm{GV}_{2} \mathrm{P}\right)$ between Ala- $\beta \mathrm{CH}_{3}$ and $\mathrm{Val}_{2}-\mathrm{NH}$ signals, suggesting a $\beta$ (II)-turn of the polypentapeptide; the detection of the corresponding crosspeak between Ala- $\alpha \mathrm{CH}$ and $\mathrm{Val}_{2}-\mathrm{NH}$ is not sure because of signal crowding. Any other crosspeak confirming a systematic $\beta$ (II)-turn of the backbone cannot be detected. Considering the fact that narrow signals (such as that of Ala- $\beta \mathrm{CH}_{3}$ ) generally give crosspeaks emerging more easily above the noise, one has to interpret this result as a proof of a $\beta$ (II)-turn at the Ala residue in poly $\left(\mathrm{AV}_{1} \mathrm{GV}_{2} \mathrm{P}\right)$ stabilized by a hydrogen bond between its carbonyl group and $\mathrm{NH}$ 
group of the $\mathrm{Val}_{2}$ residue. This finding together with the results from Raman spectroscopy given above indicating the presence of the $\beta$ (II)-turn on the Gly residue in poly $\left(\mathrm{G}_{1} \mathrm{~V}_{1} \mathrm{G}_{2} \mathrm{~V}_{2} \mathrm{P}\right)$ is in full agreement with the predictions $[3,9-11]$ of the formation of a $\beta$-spiral above the inverse transition temperature.

\section{Conclusion}

Temperature dependences of Raman spectra and model DFT calculations of two polypentapeptides show that observed conformational changes at the inverse temperature transition in poly $\left(G_{1} V_{2} G_{1} V_{2} P\right)$ correspond to the formation of the $\beta$ (II)-turn on $\mathrm{Gly}_{1} \cdot{ }^{1} \mathrm{H}-{ }^{1} \mathrm{H}$ NOESY manifests vicinity of Ala and Val 2 residues in poly $\left(\mathrm{AV}_{1} \mathrm{GV}_{2} \mathrm{P}\right)$ at $301 \mathrm{~K}$, which indicates that a $\beta(\mathrm{II})$-turn is present at the Ala site. It can be concluded that in both studied polypentapeptides the $\beta$ (II)-turn structure is formed on the residue located between Pro and Val 1 .

\section{Acknowledgement}

Support of this work by the Grant Agency of the Czech Republic (Grant No. 203/00/1320) and the Grant Agency of Academy of Sciences of the Czech Republic (Grant No. IAA4050208) is gratefully acknowledged.

\section{References}

[1] D.W. Urry, Angew. Chem. Int. Ed. Engl. 32 (1993), 819-841.

[2] P. Schmidt, J. Dybal, J.C. Rodríguez-Cabello and M. Alonso, Biopolymers (Biospectroscopy) 62 (2001), $150-157$.

[3] D.W. Urry, J. Protein Chem. 7 (1988), 1-34.

[4] J.C. Rodríguez-Cabello, M. Alonso, T. Pérez and M.M. Herguedas, Biopolymers 54 (2000), 282-288.

[5] M. Alonso, D. Arranz, V. Reboto, and J.C. Rodríguez-Cabello, Macromol. Chem. Phys. 202 (2001), 3027-3034.

[6] E.W. Small, B. Fanconi and W.L. Peticolas, J. Chem. Phys. 52 (1970), 4369-4379.

[7] M.J. Frisch, G.W. Trucks, H.B. Schlegel, G.E. Scuseria, M.A. Robb, J.R. Cheeseman, V.G. Zakrzewski, J.A. Montgomery, Jr., R.E. Stratmann, J.C. Burant, S. Dapprich, J.M. Millam, A.D. Daniels, K.N. Kudin, M.C. Strain, O. Farkas, J. Tomasi, V. Barone, M. Cossi, R. Cammi, B. Mennucci, C. Pomelli, C. Adamo, S. Clifford, J. Ochterski, G.A. Petersson, P.Y. Ayala, Q. Cui, K. Morokuma, D.K. Malick, A.D. Rabuck, K. Raghavachari, J.B. Foresman, J. Cioslowski, J.V. Ortiz, A.G. Baboul, B.B. Stefanov, G. Liu, A. Liashenko, P. Piskorz, I. Komaromi, R. Gomperts, R.L. Martin, D.J. Fox, T. Keith, M.A. AlLaham, C.Y. Peng, A. Nanayakkara, M. Challacombe, P.M.W. Gill, B. Johnson, W. Chen, M.W. Wong, J.L. Andres, C. Gonzalez, M. Head-Gordon, E.S. Replogle and J.A. Pople, Gaussian 98, Revision A.9, Gaussian, Inc., Pittsburgh, PA, 1998.

[8] D. Kurková, J. Kř́̌ž, P. Schmidt, J. Dybal, J.C. Rodríguez-Cabello and M. Alonso, Biomacromolecules, submitted.

[9] M.A. Khaled, K.U. Prasad, C.M. Venkatachalam and D.W. Urry, J. Am. Chem. Soc. 107 (1985), 7139-7145.

[10] B. Li, D.O.V. Alonso, B.J. Bennion and V. Daggett, J. Am. Chem. Soc. 123 (2001), 11 991-11 998.

[11] D.W. Urry, T.L. Trapane, H. Sugano and K.U. Prasad, J. Am. Chem. Soc. 103 (1981), 2080-2089. 


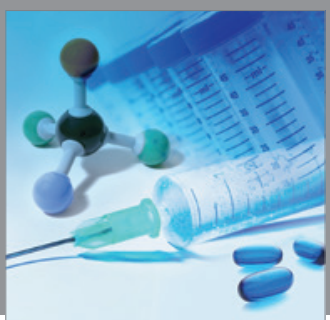

International Journal of

Medicinal Chemistry

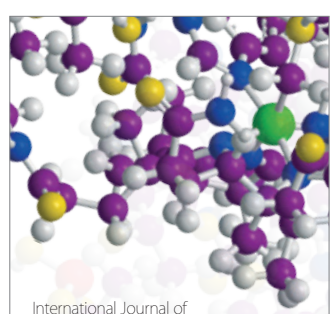

Carbohydrate Chemistry

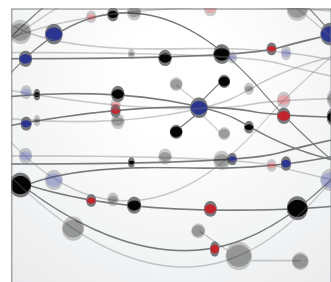

The Scientific World Journal
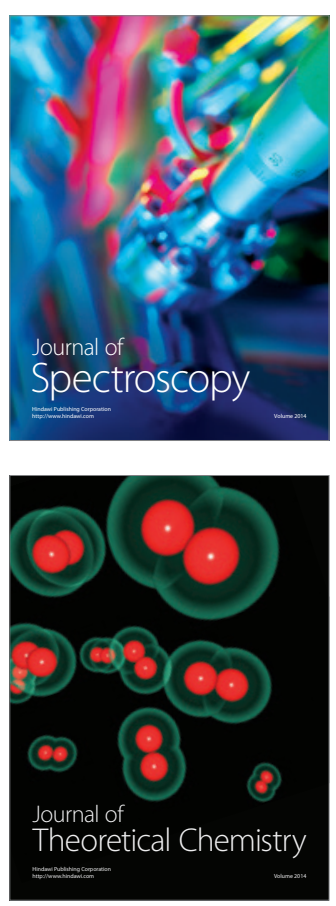
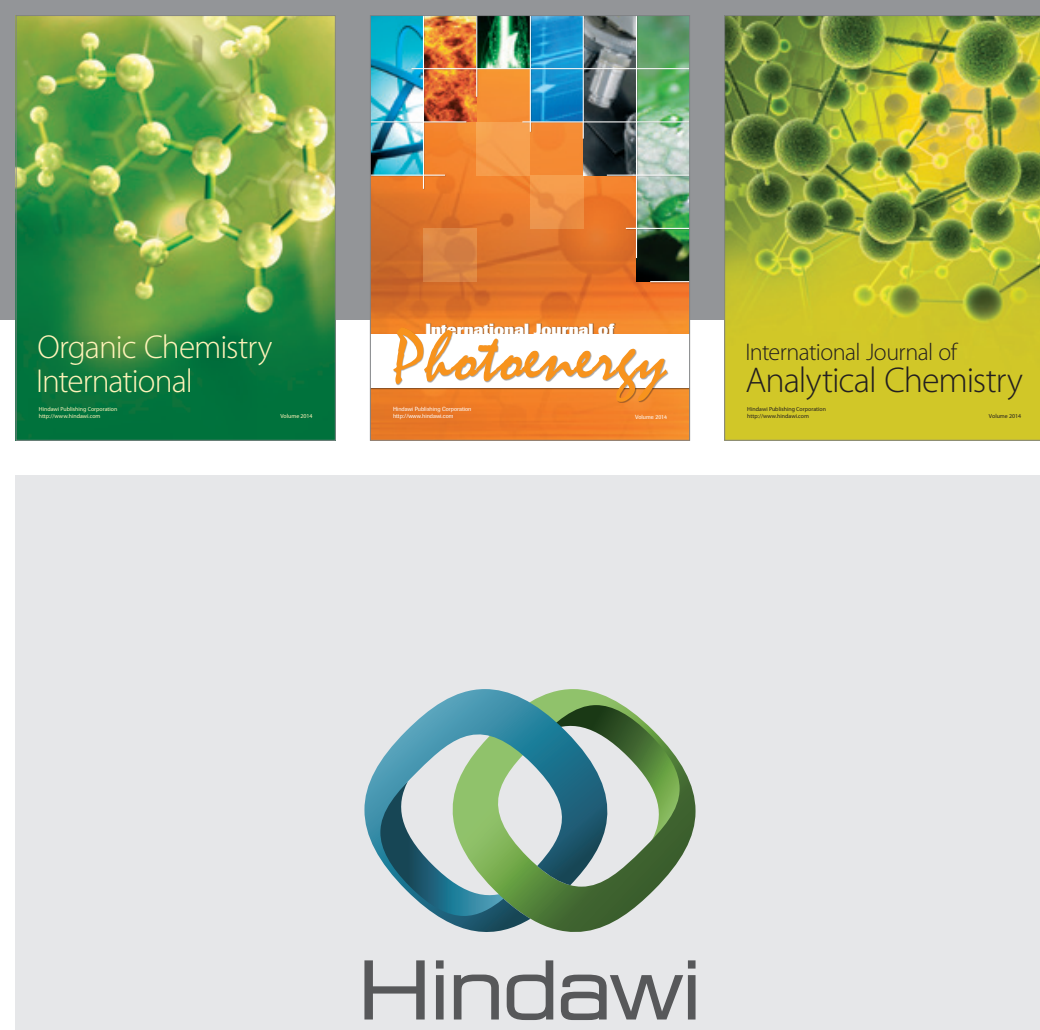

Submit your manuscripts at

http://www.hindawi.com
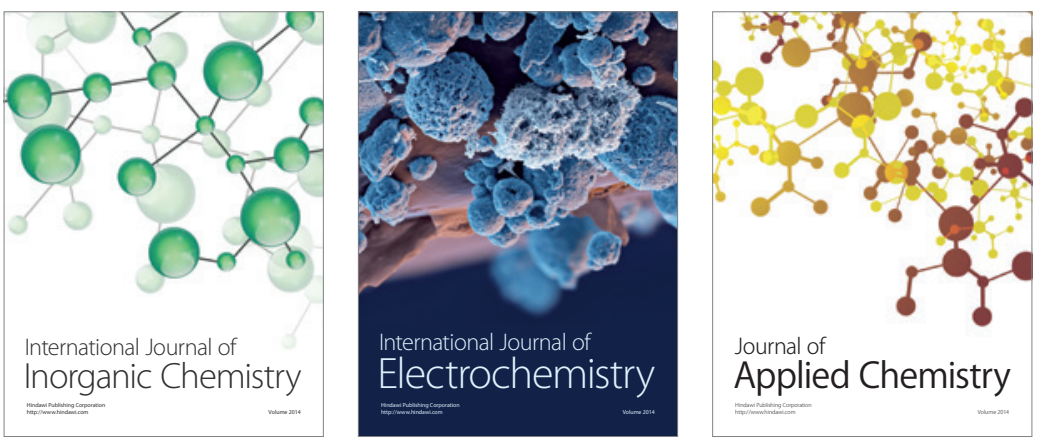

Journal of

Applied Chemistry
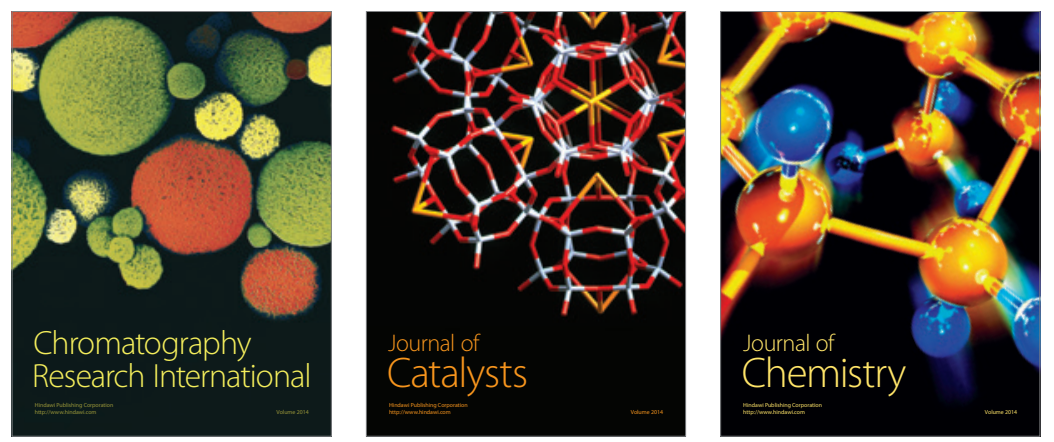
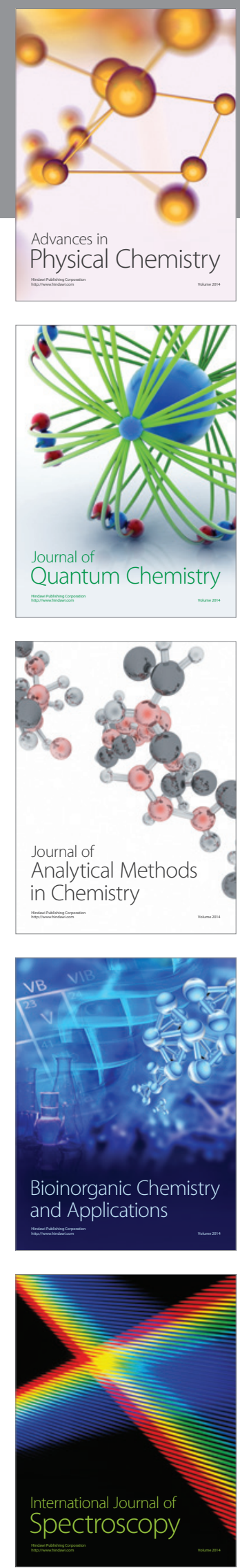